\title{
Perception of Quality of Life of People with Kidney Transplantation and Transplant Candidates in Merida, Yucatan, Mexico
}

\author{
May-Uitz $\mathrm{S}^{1 *}$, Medina-Escobedo $C^{2}$, Puch-Ku E ${ }^{1}$, Velázquez-Poot $\mathrm{G}^{1}$, May-Euán $\mathrm{F}^{1}$ and Aguillar- \\ Castillejos $\mathbf{L F}^{2}$ \\ ${ }^{1}$ Facultad de Enfermería. Universidad Autónoma de Yucatán, Mexico \\ ${ }^{2}$ Unidad Médica de Alta Especialidad. IMSS, Mexico \\ *Corresponding author: Saúl May Uitz, Facultad de Enfermería, Universidad Autónoma de Yucatán, Mexico
}

\begin{abstract}
ARTICLE INFO
Received: December 14, 2021

Published: 櫘 December 20, 2021

Citation: May-Uitz S, Medina-Escobedo C, Puch-Ku E, Velázquez-Poot G, MayEuán F. Perception of Quality of Life of People with Kidney Transplantation and Transplant Candidates in Merida, Yucatan, Mexico. Biomed J Sci \& Tech Res 40(4)-2021. BJSTR. MS.ID.006485.
\end{abstract}

Keywords: Perception; Quality of Life; People; Kidney Transplant; Kidney Diseases. DeCS
SUMMARY

Objective: To analyze the perception of quality of life of people with kidney transplantation and kidney transplant candidates treated at the High Specialty Medical Unit of Mérida.

Materials and Methods: qualitative study with interpretative phenomenological approach, intentional sampling, the final sample was made up of 11 people with a history of CKD: 7 candidates to receive kidney transplantation and 4 transplanted; data were collected through semi-structured interviews conducted during their follow-up consultations which were analyzed through content analysis.

Results: The categories analyzed were concept of quality of life with its domains: physical, economic, family, and social. Most of the participants said that quality of life is to be well physically, mentally, and emotionally, as well as to have all the basic services and not depend on renal replacement treatments: dialysis or hemodialysis.

Conclusions: A perception of absolute quality of life or free of discomfort is not achieved and human responses that require care and interventions to achieve the highest level of well-being are still manifested. The construction of the concept of quality of life includes physical, mental, personal, and social elements feasible to document and in which to exercise interventions for the benefit of the people treated and their families, it is evident that human responses do not only obey physiological needs.

\section{Introduction}

Chronic kidney disease (CKD) affects around $11 \%$ of the population over the age of 20 globally, with an increase in incidence in recent years [1]. Peritoneal dialysis, hemodialysis and kidney transplantation are treatments that have been effective in increasing the life expectancy of people with CKD [1,2]. In the last three decades, the analysis of quality of life has been integrated as an indicator of the evolution of health status in patients with CKD to see beyond the number of years of survival. Quality of life is, according to the WHO, "the perception that an individual has of his place in existence, in the context of the culture and value system in which he lives and in relation to his objectives, his expectations, his norms, his concerns. It is a concept that is influenced by the physical health of the subject, their psychological state, their level of independence, their social relationships, as well as their relationship with the environment." This concept encompasses objective and subjective aspects that reflect the degree of physical, emotional, social and economic well-being of each individual. 
The analysis of the quality of life in people with CKD allows us to understand the impact of the disease and its treatment, to know more about patients, how they evolve and how they adapt to organic alteration $[3,4]$. Currently, the analysis of quality of life in people with CKD seeks to generate evidence, qualitative and quantitative, to facilitate: the process of assessing human needs and the implementation of quality interventions in the care sectors [5]. In the health sciences, phenomenological research, and those with a qualitative approach in general, generate evidence that serves as a guide to practice sensitive to the realities of the people to whom care is directed, to their cultural diversity and to the contexts in which their lives unfold $[6,7]$.

In studies related to quality of life in transplanted people and candidates for kidney transplantation, participants manifest as the main human responses: recurrent hospitalizations, uncertainty about the work situation, deterioration of body image, deterioration of sexual functionality, dependence on third parties, stress and guilt [2,8-12]. Specifically, people who are candidates for kidney transplantation manifest as the main human responses: anxiety and depression [13,14]. Transplanted individuals report acute rejections, medication side effects, and emotional instability; [12-15,16] immediately, after transplantation, they may perceive release with respect to dependence on renal replacement therapy, but as time goes by, they have to face various adaptation problems: side effects of medications, medical and social complications, among the latter the return to work, social and family life $[12,16,17]$. The analysis of quality of life, with its respective components and human responses in patients with a history of CKD is recent. Therefore, the needs inherent in the nursing care process may go unnoticed when directing care for people with these characteristics. Although there are numerous studies that quantitatively address health-related quality of life, $[4,18,19]$ qualitative studies such as the present one provides particular evidence to integrate it into the holistic process of the nursing-patient relationship at different levels of care $[13,20]$. Therefore, the objective of this study is to analyze the perception of quality of life of people with kidney transplantation and kidney transplant candidates treated at the High Specialty Medical Unit of Mérida, to identify the related human responses through an interpretive phenomenological approach.

\section{Methodology}

\section{Design}

A qualitative study was conducted with an interpretative phenomenological approach. From this design it is possible to reach the understanding of the experiences and the articulation of similarities and differences in the meanings and human experiences of people with kidney transplantation and candidates for kidney transplantation. Although it is not possible to make generalizations of the results of this study, particular data are reached with transferability to other populations with similar characteristics $[6,7,14]$. This article followed the COREQ [Consolidated criteria for reporting qualitative research] criteria to enhance its quality and clarity [21].

\section{Study and Sampling Population}

An intentional sampling was carried out, obtaining a final sample consisted of 11 people with a history of ERD: 7 candidates to receive kidney transplant and 4 transplanted, who received health services in the High Specialty Medical Unit of Mérida [UMAE] of the Mexican Institute of Social Security [IMSS]during the period from November 2019 to February 2020.

\section{Data Collection}

Data were collected through semi-structured interviews conducted during their follow-up consultations. Interviews lasted 30 to 40 minutes, were recorded in audio format, and field notes were taken. Table 1 presents the questions asked during the semistructured interviews.

Table 1: Semi-structured interview questions.

\begin{tabular}{|c|c|}
\hline Kidney Transplant Candidates & With Kidney Transplant \\
\hline $\begin{array}{c}\text { 1.According to your culture, what } \\
\text { is quality of life for you? }\end{array}$ & $\begin{array}{c}\text { 1. According to your culture What } \\
\text { is quality of life for you? }\end{array}$ \\
\hline $\begin{array}{c}\text { 2. From that definition, what } \\
\text { changes in your life have you } \\
\text { noticed because of the problem } \\
\text { you present? }\end{array}$ & $\begin{array}{c}\text { 2. From that definition, was there } \\
\text { any change in your quality of life } \\
\text { before and/or after the transplant? }\end{array}$ \\
\hline $\begin{array}{c}\text { 3. What do you think can change in } \\
\text { your life with the transplant? }\end{array}$ & $\begin{array}{c}\text { 3. Mention all aspects of your life } \\
\text { that are important to you that } \\
\text { could be affected by the transplant. }\end{array}$ \\
\hline $\begin{array}{c}\text { 4. Tell me, how has your family } \\
\text { of life according to the concept you } \\
\text { gave me? }\end{array}$ & $\begin{array}{c}\text { 4. Tell me how has your family } \\
\text { relationship influenced that } \\
\text { quality of life? }\end{array}$ \\
\hline $\begin{array}{c}\text { 5. Tell me, how has this waiting } \\
\text { process influenced your family, } \\
\text { friends and/or neighbors? }\end{array}$ & $\begin{array}{c}\text { 5. Tell us about the influence the } \\
\text { transplant has and/or had on } \\
\text { your relationships with friends, } \\
\text { neighbors, and acquaintances. }\end{array}$ \\
\hline $\begin{array}{c}\text { 6. How do you think it has changed } \\
\text { you in your mood with your family } \\
\text { and friends because of the waiting }\end{array}$ & $\begin{array}{c}\text { 6. Are you happy with the change } \\
\text { that the transplant brought about } \\
\text { in your relationships with friends, } \\
\text { neighbors, and acquaintances? }\end{array}$ \\
\hline $\begin{array}{c}\text { your life been like to this day? } \\
\text { prom the day you were told you }\end{array}$ & $\begin{array}{c}\text { 7. From the day of the transplant to } \\
\text { the present day, what has your life } \\
\text { been like? }\end{array}$ \\
\hline
\end{tabular}

\section{Ethical Considerations}

The study respects ethical principles: beneficence, nonmaleficence, justice and autonomy. The research study protocol, with folio R-2018-785-129, was approved by the ethics committee of the High Specialty Medical Unit of the Mexican Social Security Institute. The testimonies presented herein are referenced with codes to safeguard the identity of the participants. 


\section{Information Processing}

Semi-structured interviews were transcribed verbatim and then analyzed using content analysis. This analysis process consisted of:

1. Encoding the data and establishing a data index.

2. Categorize the content of the data into meaningful categories; and

Table 2: Categories for grouping and analysis of qualitative data.
3. Determine the topics related, in this case human responses, to the previously defined categories $[7,22]$. In the results section, tables are presented that allow to visualize the categories of analysis delimited in Table 2 from Urzúa and Caqueo [23], the human responses within the categories and, finally, testimonies of the participants; all of the above accompanied by interpretive narrative.

\begin{tabular}{|c|c|}
\hline Category & Definition \\
\hline \multirow[t]{2}{*}{ Quality of life } & $\begin{array}{c}\text { An individual's perception of his or her place in existence, in the context of the culture and value system in which he or she lives } \\
\text { and, in a relationship, }\end{array}$ \\
\hline & *Familiar with their goals, their expectations, their norms, their concerns. \\
\hline * Physical & $\begin{array}{l}\text { Referring to the state of physical health of the student to be evaluated, such as the issue of sleep, their diet, the proper use or not of } \\
\text { free time, the suffering or not of any disease that threatens to prostrate the person. }\end{array}$ \\
\hline * Economical & $\begin{array}{l}\text { Referred to the acquisition of food, accommodation, comfort and socioeconomic status of the person, as well as their income and } \\
\text { economic security. It also refers to skills and abilities that could provide training opportunities for personal growth. }\end{array}$ \\
\hline * Familiar & $\begin{array}{l}\text { Referred to valuable relationships with family, as well as friendship relationships, social interactions with acquaintances or } \\
\text { classmates; without neglecting the quality and satisfaction associated with interpersonal relationships. }\end{array}$ \\
\hline * Emotional & $\begin{array}{l}\text { It refers to satisfaction, happiness, feeling of general well-being, as well as the perception of the fulfillment of personal goals and } \\
\text { aspirations. }\end{array}$ \\
\hline
\end{tabular}

Note: * Categories of the concept of quality of life from Urzúa and Caqueo.

\section{Quality Criteria}

Once the transcript of the interviews was completed, the 11 participants were asked to verify that the information interpreted was correct. Also the protocolization related to the organization of the data, the detailed and meticulous description of the selection of the sample and the context in which the study is carried out, facilitate the possibility of transfer and reproducibility of the same in similar conditions, thus providing another criterion of qualitative quality.

\section{Results}

Characteristics of the participants Years of age were a median of 37 [mean 39] and $\mathrm{SD}=13$ in the 11 participants. In people who were candidates for RT, the median was 37 [mean 41] and in those with RT it was 35.7 years [mean 41), respectively. In the latter group two people were 6 months or less old after receiving RT, one was 1 year old, and one person was 10 years old. Table 3 shows that the majority of the total sample was made up of men who worked as employees.

Table 3: Sociodemographic characteristics of the 11 participants included in the study.

\begin{tabular}{|c|c|c|c|}
\hline \multicolumn{2}{|c|}{ Sociodemographic variables } & Con TR (n=4) & TR candidates (n=7) \\
\cline { 2 - 4 } & Male & $3(75)$ & $4(57)$ \\
\hline \multirow{2}{*}{ Sex } & Female & $1(25)$ & $3(43)$ \\
\cline { 2 - 4 } & Housewife & - & $1(14)$ \\
\cline { 2 - 4 } Employment & Employee & $3(75)$ & $4(57)$ \\
\cline { 2 - 4 } & Unemployed & $1(25)$ & $2(29)$ \\
\hline
\end{tabular}

\section{Quality of Life: Perception in Kidney Transplant Candidates}

Table 4 shows the interpretations related to the categories: concept of quality of life with their respective domains: physical, economic, family, and social, then the identified human responses are presented. Most of the participants said that quality of life is to be well physically, mentally, and emotionally, as well as to have all the basic services and not depend on renal replacement treatments: dialysis or hemodialysis. In the physical domain, people highlight discomfort, pain and discomfort related to the procedures of renal replacement therapies or the body itself: chronic or bone pain, for example, these human responses largely condition the inability 
to enter the labor field. In the economic domain, the participants report that they are unable to carry out the activities of any employment due to physical disability, and therefore, consider that their monetary income from a trade or employment is limited, scarce or null. In addition, they stressed that the economic

Table 4: Quality of life: perception of kidney transplant candidates. resources are focused on financing the management of the health itself: laboratory tests, transportation, extraordinary treatments, appointments, and medical consultations, among others; these efforts are complicated precisely by the lack of monetary inputs.

\begin{tabular}{|c|c|c|}
\hline Categories & $\begin{array}{l}\text { Interpreted human } \\
\text { responses }\end{array}$ & Testimonies $n=7$ \\
\hline $\begin{array}{l}\text { Concept of quality } \\
\text { of life }\end{array}$ & $\begin{array}{l}\text { Independence: physical, } \\
\text { economic and social / Physical } \\
\text { and mental well-being }\end{array}$ & $\begin{array}{l}\text { 1. It is to be healthy, to be well of mind and basically, the most important thing, is to have health } \\
\text { physically and mentally to be able to be well. } \\
\text { 2. It is to live with dignity, both in health, food and in itself, to have good health. } \\
\text { 6. Do not depend on any medical treatment, be able to be free from consultations. } \\
\text { 7. It is the way we live, the way I am living, how I carry my food, the house, how I pay for } \\
\text { electricity, rent, water. }\end{array}$ \\
\hline *Physical & Pain and discomfort & $\begin{array}{l}\text { 1. Physical pain, bone pain. I've been with kidney failure for eleven years. } \\
\text { 7. Dialysis is painful and uncomfortable }\end{array}$ \\
\hline${ }^{*}$ Economical & Inability to enter the workforce & $\begin{array}{l}\text { 1. I can't work anymore. } \\
\text { 2. Difficult because of medical outings and appointments. } \\
\text { 3. Many expenses for travel, treatments, appointments, and diet. } \\
\text { 4. Job opportunities, I can't take them. } \\
\text { 7. He earned well and now with the pension it is not enough. }\end{array}$ \\
\hline *Familiar & $\begin{array}{l}\text { Perception of "being a severe } \\
\text { burden" for family members }\end{array}$ & $\begin{array}{l}\text { 1. They accompany me to sessions and medical appointments. There is always someone with } \\
\text { me, the support of the family is the most important thing. } \\
\text { 2. I'm sorry to be a burden. They understand the time I can't be home. } \\
\text { 3. If I didn't have my family I would have already left. I feel that for them it is tired. } \\
\text { 6. The tension in patients without success in their first transplant and who now waits again is } \\
\text { remarkable. When I relapsed, they focused on me again? } \\
\text { 7. I would be alone without my children, absolutely alone. }\end{array}$ \\
\hline * Emotional & Low self-esteem & $\begin{array}{l}\text { 1. I adapted. Moments of depression. Sad because I didn't see the possibility of improving. If it } \\
\text { comes (the transplant) it is good but, then there is fear. } \\
\text { 2. Frustrating not knowing what will happen, if the transplant can come and if I can be suitable } \\
\text { for it to be achieved or I will no longer be there. My children depend on my strength, so I try to } \\
\text { be strong. } \\
\text { 3. You feel like you can't anymore. }\end{array}$ \\
\hline
\end{tabular}

Note: *Categories of the concept of quality of life from Urzúa and Caqueo.

In the family domain, people identify the importance of the support, care, and understanding they receive, received, and expect to receive from their family in the ups and downs related to their state of health and well-being. In this regard, some express feelings of feeling a burden for their relatives for the extra activities that the latter perform in health management, which generates tension and uncertainty. However, the interviewees expressed the motivation generated by their family environment: mothers, children and grandchildren, among other ties, drive the desire to want to get out of their problem and be patients waiting for the transplant. In the emotional domain, each of the people interviewed expressed their affectation at different points that leads them to present low self-esteem: fear, frustration, depression, sadness and uncertainty are some of the emotions they expressed among their testimonies. Participants follow a continuous coping process, because not every day they feel with all the energy and motivation to continue with everyday life. The emotional perception of the interviewees was reflected in their features during the interviews, they touched points that led them to cry, they expressed how difficult it is to live with a dysfunctional organ, the uncertainty before the latent complications that can even make them lose their lives. 


\section{Quality of life: Perception in People with Kidney Transplantation}

Table 5 shows that most participants consider that quality of life involves physical, environmental and personal well-being as components. For one of the interviewees, it means no longer relying on external factors to sustain life; another considered that the longer he can extend his life is better for the quality of it, considered that discomforts are companions of life. In the physical domain, the interviewees expressed the freedom to perform various activities and eat food without affecting their quality of life. They expressed that they could move and travel without thinking about the need to carry too many supplies related to their treatment. They also stated that they can eat food without causing discomfort or altering their clinical parameters, especially water, which was previously restricted. In the economic domain, participants report that they have time and autonomy to build opportunities for insertion into trades, jobs and vocational or educational training. One case mentioned that the ability to acquire economic resources improves their quality of life, another participant reports that they can work freely without thinking about the times of some renal therapy, finally, a case refers that they returned to normal by fully taking these opportunities that they previously addressed discreetly.

Table 5: Quality of life: perception of kidney transplants.

\begin{tabular}{|c|c|c|}
\hline Components & Human Responses & Testimonies $n=4$ \\
\hline $\begin{array}{c}\text { Concept of quality of } \\
\text { life }\end{array}$ & $\begin{array}{l}\text { Physical, environmental, } \\
\text { and personal well-being }\end{array}$ & $\begin{array}{l}\text { 8. Way to improve the environment and one's own life. } \\
\text { 9. No setbacks, everything in order, all laboratories well. } \\
\begin{array}{c}\text { 10. Lead daily life without relying on hospital visits or medications, without episodes of } \\
\text { depression. }\end{array} \\
\begin{array}{c}\text { 11. Survival in years, lengthening. Maybe there will be deterioration, but you don't depend on } \\
\text { machines. }\end{array}\end{array}$ \\
\hline *Physical & $\begin{array}{l}\text { Physical and nutritional } \\
\text { autonomy }\end{array}$ & 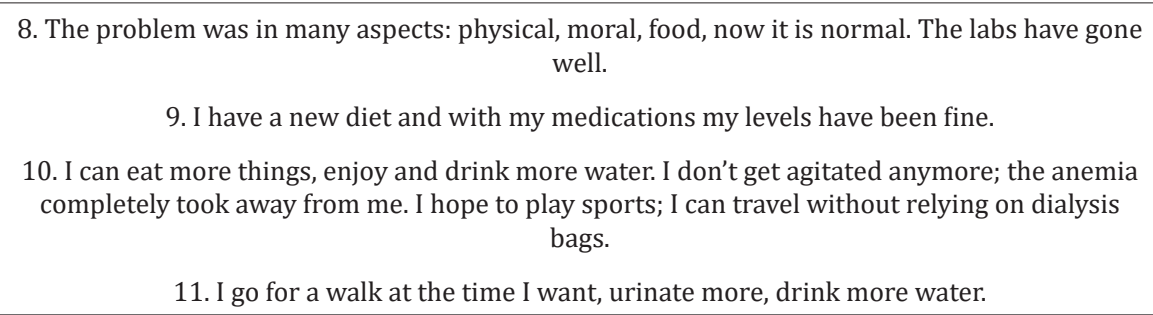 \\
\hline *Economical & $\begin{array}{l}\text { Time and autonomy to } \\
\text { build opportunities }\end{array}$ & $\begin{array}{l}\text { 8. I no longer have to go to the hospital every week for hemodialysis, I only go for consultation. } \\
\qquad 9 \text { I can work tending to the family store, do more activities and walk better. } \\
\text { 10. I never stopped working and studying, I finished high school and career. I walk quite a bit. I } \\
\text { can take care of the business we have. I was back to normal. } \\
\text { 11. More possibilities to study, seek better quality of life and self-improvement. I can commute } \\
\text { to work }\end{array}$ \\
\hline *Familiar & $\begin{array}{l}\text { Perception of "being } \\
\text { moderate burden" for } \\
\text { family members }\end{array}$ & $\begin{array}{l}\text { 8. It is less the burden for them, help is necessary, they give you motivation. I used to see them } \\
\text { go out of their way because of hospital visits. } \\
\text { 9. My son told me that he donated to me, and I told him no, he was going to be unarmed. I feel } \\
\text { like it's one less burden, I feel happier. } \\
\text { 10. We live together more, before they carried dialysis boxes and the machine; they didn't enter } \\
\text { the room. } \\
\begin{array}{l}\text { 11. Even if you are distant (physically), they are always there to support you. I'm enjoying mine; } \\
\text { they tell me not to lock myself up and go out and enjoy. }\end{array}\end{array}$ \\
\hline *Emotional & $\begin{array}{l}\text { Confidence and emotional } \\
\text { balance }\end{array}$ & $\begin{array}{l}\text { 8. I was born again. I haven't had any relapses. } \\
\begin{array}{c}\text { 9. I don't depend on dialysis; I can talk to my neighbors. I was (and am) in the hands of the } \\
\text { doctor and there is nothing to worry about. }\end{array} \\
\begin{array}{c}\text { 10. The first few days I was in isolation, it overwhelmed me. More possibility to improve quality } \\
\text { of life }\end{array} \\
\begin{array}{c}\text { 11. Second chance God gave you; once I visited a psychiatrist, it worked out more for me to have } \\
\text { faith. People with disease experience problems; I was always positive, I learned it from a dialysis } \\
\text { nurse. }\end{array}\end{array}$ \\
\hline
\end{tabular}

Note: *Categories of the concept of quality of life from Urzúa and Caqueo. 
In the family domain, the perception and feelings of being considered a burden on their families has decreased along with the amount of care related to renal replacement therapies from which transplanted participants are already exempt; people mentioned that despite the constant support of their relatives there was a physical distancing seeking to reduce the crossing of infections, a situation that in recent times has ended and they can share more time and experiences together. In the emotional domain, trust and emotional balance were interpreted in the participants. Two people mentioned that they feel they have a new opportunity before life to restart it and have new experiences that they previously did not consider possible. Two people referred to the need to have confidence and know how to take the advice of health personnel: doctors and nurses. Finally, one participant described that he was overwhelmed by living a few days in isolation after his transplant, necessary to prevent infections, but at the same time accepts that it is necessary to improve his quality of life.

\section{Discussion}

The quality of life of people with a history of renal pathologies is affected since the first clinical manifestations, the QoL in this sector has shown deficiencies, low levels or areas of opportunity with respect to the rest of the population [24]. Physical, environmental and personal well-being are part of the conception of quality of life in people with renal pathologies, whether they have been transplanted or not. In the early stages of the disease there are a series of negative perceptions of the disease and its mediate and immediate quality of life that, ultimately, can influence their coping actions, these perceptions can trigger anxiety, depression, coping, autonomy, self-esteem and accelerated progression of the disease [25]. In the identification of human responses in patients with chronic kidney disease, the main physiological risks related to this pathology have been highlighted. Farias et. al. points out the overstating of biological and complication-related human responses by nursing staff providing care to patients with nephropathies in a renal center. Among 24 diagnostic labels identified, the most frequent were "risk of infection", "excess fluid volume", "hypothermia", among others whose main domains were located in Safety / Protection and Activity / Rest, on the other hand, "low situational self-esteem" was ranked $16^{\text {th }}$ in frequency [26] corresponding to the Self-perception domain in the NANDA-I [20]. The above shows what Spilogon et. al. points out as an area of opportunity in the nursing process because it has the flexibility and openness to consider the perceptions and preferences of the user, in this case of the patient with nephropathies [27].

In the emotional category, low self-esteem was detected in participants with CKD without transplantation, and that is that a patient with CKD has needs for recognition and esteem, so the people in charge of their care should promote favorable behaviors in coping with the pathology and attachment to treatment, avoiding judging and repressing the failures of our human condition [28]. In contrast, participants who had received a kidney transplant manifested confidence and emotional balance, something that could be considered normal after receiving the expected transplant according to Tucker, et. al. [29]. From a quantitative approach Rocha et. Al. point out that the higher the quality of life, the better the assessment of the self-esteem of people with chronic kidney disease after transplantation [30].

In the economic category, while people who had not received kidney transplantation conceived the inability to enter the workforce among their perception of quality of life, those who had received kidney transplantation indicated greater time and autonomy to build job and academic opportunities. Reports indicate that patients with chronic kidney disease face many barriers to staying or joining the workforce after starting dialysis: limited opportunities, lack of financial resources to invest, fatigue and other symptoms of kidney failure, potential loss of disability benefits or medical follow-up, dialysis scheduling, and employer bias. The societal perception that patients with CKD cannot work completes a vicious cycle of low employment expectations [25,31].

In the family category, the perception of "being a burden" for family members influences is an important component in the perception of the quality of life of people with transplantation and without kidney transplantation. Evidence indicates that family members of patients with a history of renal pathologies manifest sleep interruptions, depression, anxiety, among other disorders associated with unforeseen responsibilities related to the treatment and logistics of their relatives; they must also deal with insufficient information, medication regimen and be accompanied by periodic hospitalizations [32]. NANDA International classifies problems into plausible diagnostic labels of interventions focused on promoting the health of individuals, the family. and community, we can mention: Risk of fatigue of the role of caregiver, Fatigue of the role of the caregiver, Dysfunctional family processes, Willingness to improve family processes, among others [20].

In the physical category, participants without kidney transplantation are identified as a condition for quality of life, a common and often severe manifestation in various populations with CKD; with prevalence's of $40 \%$ to $60 \%$ is a strong imperative to establish the management of chronic pain as a clinical and research priority [33]. In this regard, the labels acute and chronic pain are available in NANDA-I [20]. Although pain and physical limitation decreases after a kidney transplant, it is important to mention that the physical and nutritional autonomy indicated by the participants of the present can generate an excess of confidence and the acquisition of unhealthy practices. Physical training regulated by physiotherapy specialists appears to be safe in kidney 
transplant recipients and is associated with improved quality of life and exercise capacity [34]. With respect to diet, the Mediterranean and DASH (Dietary Approaches to Stop Hypertension) diets have been shown to be the most beneficial dietary patterns for the population after kidney transplantation by focusing on less meat and processed foods, while increasing intake of fresh foods and plant-based options. [35]. Knowledge and awareness in the renal transplant population should be a cornerstone of therapy and an integral part of nursing responsibilities. Therefore, nurses should educate patients about self-care behaviors and remind them of the dangerous complications of abandoning them [28].

In participants who had not received a kidney transplant, there was an expectation of receiving a kidney transplant to improve their quality of life and from it to improve their quality of life. In this aspect we can mention the benefits before the expectation of receiving a kidney transplant mentioned by Santos et. al. who in a group of people with Brazilian nephropathies detected that patient who were not waiting for transplantation were at risk of poor quality of life, mainly in the emotional and physical aspects; those who were not awaiting transplantation died more frequently in the next 12 months [36]. However, betting on kidney transplantation to improve the quality of life in patients with nephropathies is not entirely recommended, in this regard we can cite the studies of Schulz et. al. and Smith et. al. published in 2014 and 2019, [29,37] who reported that before transplantation patients can overestimate gains in quality of life without finding significant improvements in quality of life after being transplanted.

Kidney transplantation is not a guarantee of improvement in quality of life in all patients with nephropathies, in the present study, those people who had received the kidney transplant did not consider an absolute improvement in their quality of life. The literature notes that kidney transplants can provide dramatic improvements in quality of life and health status, however, the effects on improvement are not universal and patients live in constant uncertainty as they are aware of the likelihood of graft dysfunction [29]. There are samples that have indicated that the expectation about the functionality or rejection of the graft generates greater fear and uncertainty than death itself [38]. The results on the perception of quality of life in people receiving renal replacement therapy support the trend of the last decade focused on the analysis of this category beyond only assessing life expectancy [39]. The limitations of the present are the risk of bias due to the same interpretative approach and the inability to generalize the results to the study population. To compensate for the above, criteria of methodological rigor were followed and from a particular context the search for generalities was made, reinforcing the results with respect to other studies [21].

\section{Conclusion}

In transplant patients, a perception of absolute or discomfortfree quality of life is not achieved and human responses that require care and interventions to achieve the highest level of well-being are still manifested. The construction of the concept of quality of life includes physical, mental, personal and social elements feasible to document and in which to exercise interventions for the benefit of the people treated and their families, it is evident that human responses do not only obey physiological needs.

\section{Conflict of Interest}

No conflict of interest with any institution/organization.

\section{References}

1. Webster AC, Nagler EV, Morton RL, Masson P (2021) Chronic Kidney Disease. The Lancet. Lancet Publishing Group 389: 1238-1252.

2. Sitjar-Suñer M, Suñer-Soler R, Masià-Plana A, Chirveches-Pérez E Bertran-Noguer C, et al. (2020) Quality of Life and Social Support of People on Peritoneal Dialysis: Mixed Methods Research. Int J Environ Res Public Health 17(12): 4240.

3. Li Z, Zhang Y, Zhang L (2017) Evolution and future trends of integrated health care: a scientometric analysis. Int J Integr Care 17(5)

4. Rebollo-Rubio A, Morales-Asencio JM, Pons-Raventos ME, MansillaFrancisco JJ (2015) Revisión de estudios sobre calidad de vida relacionada con la salud en la enfermedad renal crónica avanzada en España. Nefrologia 35(1): 92-109.

5. Singh B, Rochow N, Chessell L, Wilson J, Cunningham K, et al. (2018) Gastric Residual Volume in Feeding Advancement in Preterm Infants (GRIP Study): A Randomized Trial. J Pediatr 200: 79-83.e1.

6. Expósito Concepción MY, Villarreal Cantillo E, Palmet Jiménez MM Borja González JB, Segura Barrios IM, et al. (2019) La fenomenología, un método para el estudio del cuidado humanizado. Rev Cuba Enfermería 35(1) Enero-Marzo.

7. Rodriguez A, Smith J (2018) Phenomenology as a healthcare research method. Evid Based Nurs [Internet] 21(4):118.

8. Moya Ruiz MA (2017) Estudio del estado emocional de los pacientes en hemodiálisis. Enferm Nefrol 20(1): 48-56.

9. Rodr C (2008) Calidad de vida en pacientes nefrópatas con terapia dialítica* 13(1): 15-22.

10. Ottaviani AC, Souza ÉN, Drago N de C, de Mendiondo MSZ, Pavarini SCI, et al. (2014) Esperança e espiritualidade de pacientes renais crônicos em hemodiálise: Estudo correlacional. Rev Lat Am Enfermagem 22(2): 248-254.

11. Jiménez Ocampo VF, Giraldo BP, Del Pilar Botello Reyes A (2016) Spiritual perspective and health-related quality of life of dialyzed patients. Rev Nefrol Dial y Traspl 36(2): 91-98.

12. Gumabay FM, Novak M, Bansal A, Mitchell M, Famure 0, et al. (2018) Pre-transplant history of mental health concerns, non-adherence, and post-transplant outcomes in kidney transplant recipients. J Psychosom Res 105: 115-124. 
13. Gómez Tovar LO, Díaz Suarez L, Cortés Muñoz F (2016) Cuidados de enfermería basados en evidencia y modelo de Betty Neuman, para controlar estresores del entorno que pueden ocasionar delirium en unidad de cuidados intensivos. Enfermería Global. Scieloes 15: 49-63.

14. Cuesta Benjumea C de la (2010) La investigación cualitativa y el desarrollo del conocimiento en enfermería. Texto \& Contexto- Enfermagem. Scielo 19: 762-766.

15. Baines LBS, Joseph JT, Jindal RM (2002) Emotional issues after kidney transplantation: A prospective psychotherapeutic study. Clin Transplant 16(6): 455-460.

16. De Pasquale C, Luisa Pistorio M, Veroux M, Indelicato L, Biffa G, et al. (2020) Psychological and psychopathological aspects of kidney transplantation: A systematic review. Front Psychiatry 11: 1.

17. Müller HH, Englbrecht M, Wiesener MS, Titze S, Heller K, et al. (2015) Depression, anxiety, resilience and coping pre and post kidney transplantation - Initial findings from the psychiatric impairments in kidney transplantation (PI-KT)-study. PLoS One (11): e0140706.

18. (2017) Asso-Soto ME P-MMC-EJ. Calidad de vida y perspectiva espiritual de los pacientes hospitalizados con enfermedad cardiovascular. Rev Enferm IMSS 25(2): 9-17.

19. Saboya PP, Bodanese LC, Zimmermann PR, Da Silva Gustavo A, Assumpção CM, et al. (2016) Síndrome metabólica e qualidade de vida: Uma revisão sistemática. Revista Latino-Americana de Enfermagem. University of Sao Paulo, Ribeirao Preto College of Nursing Organisation 24.

20. Herdman HT, Kamitsuru S (2017) NANDA International Nursing Diagnoses: Definitions \& Classification 2018-2020. Novena, editor. Michigan: Thieme.

21. Walsh S, Jones M, Bressington D, McKenna L, Brown E, et al. (2020) Adherence to COREQ Reporting Guidelines for Qualitative Research: A Scientometric Study in Nursing Social Science, p. 19.

22. Reeson M (2020) Phenomenological research in health professions education: Methods, Data collection and Analysis.

23. Urzúa MA, Caqueo-Urízar A (2012) Calidad de vida: Una revisión teórica del concepto. Terapia psicológica. Scielocl 30: 61-71.

24. Sánchez-Cabezas AM, Morillo-Gallego N, Merino-Martínez RM, CrespoMontero R, Sánchez-Cabezas AM, et al. (2019) Calidad de vida de los pacientes en diálisis. Revisión sistemática. Enfermería Nefrológica 22(3): 239-255.

25. Clarke AL, Yates T, Smith AC, Chilcot J (2016) Patient's perceptions of chronic kidney disease and their association with psychosocial and clinical outcomes: a narrative review. Clin Kidney J 9(3): 494.

26. Farias de Queiroz Frazão CM, de Almeida Medeiros AB, Mariano Nunes de Paiva M das G, Cruz Enders B, de Oliveira Lopes MV, (2015) Nursing diagnoses and adaptation problems among chronic renal patients. Investigación y Educación en Enfermería. Scieloco 33: 119-127.

ISSN: 2574-1241

DOI: 10.26717/BJSTR.2021.40.006485

Saúl May Uitz. Biomed J Sci \& Tech Res



This work is licensed under Creative Commons Attribution 4.0 License

Submission Link: https://biomedres.us/submit-manuscript.php
27. Spigolon DN, Teston EF, Souza F de O, Santos B dos, Souza RR de, et al (2018) Nursing diagnoses of patients with kidney disease undergoing hemodialysis: a cross-sectional study. Rev Bras Enferm 71(4): 2014 2020 .

28. Poorgholami F, Javadpour S, Saadatmand V, Jahromi MK (2016) Effectiveness of Self-Care Education on the Enhancement of the SelfEsteem of Patients Undergoing Hemodialysis. Glob J Health Sci 8(2): 132.

29. Tucker EL, Smith AR, Daskin MS, Schapiro H, Cottrell SM, et al. (2019) Life and expectations post-kidney transplant: a qualitative analysis of patient responses. BMC Nephrol 20(1).

30. Rocha FL da, Echevarría-Guanilo ME, Silva DMGV da, Gonçalves N, Lopes SGR, et al. (2020) Relationship between quality of life, self-esteem and depression in people after kidney transplantation. Rev Bras Enferm 73(1): e20180245.

31. Al-Rabiaah A, Temsah M-H, Al-Eyadhy AA, Hasan GM, Al-Zamil F, et al. (2020) Middle East Respiratory Syndrome-Corona Virus (MERS-CoV) associated stress among medical students at a university teaching hospital in Saudi Arabia. J Infect Public Health 13(5): 687-691.

32. Nicole De Pasquale, Ashley Cabacungan, Patti L Ephraim, LaPricia LewisBoyér, Neil R Powe, et al. (2019) Family Members' Experiences With Dialysis and Kidney Transplantation. Kidney Med 1(4): 171-179.

33. Davison SN, Rathwell S, Ghosh S, George C, Pfister T, et al. (2021) The Prevalence and Severity of Chronic Pain in Patients with Chronic Kidney Disease: A Systematic Review and Meta-Analysis 8.

34. Ashley Takahashi, Susie L Hu, Andrew Bostom (2018) Physical Activity in Kidney Transplant Recipients: A Review. Am J Kidney Dis 72(3): 433443.

35. Goldfarb Cyrino L, Galpern J, Moore L, Borgi L, Riella LV (2021) A Narrative Review of Dietary Approaches for Kidney Transplant Patients. Kidney Int Reports 6(7): 1764-1774.

36. Paulo Roberto Santos (2011) Comparison of quality of life between hemodialysis patients waiting and not waiting for kidney transplant from a poor region of Brazil. J Bras Nefrol 33(2): 166-172.

37. Schulz T, Niesing J, Homan van der Heide JJ, Westerhuis R, Ploeg RJ, et al. (2014) Great expectations? Pre-transplant quality of life expectations and distress after kidney transplantation: A prospective study. Br J Health Psychol 19(4): 823-838.

38. Howell M, Wong G, Rose J, Tong A, Craig JC, et al. (2017) Patient preferences for outcomes after kidney transplantation: a best-worst scaling survey. Transplantation 101(11): 2765-2773.

39. Maglakelidze N, Pantsulaia T, Tchokhonelidze I, Managadze L, Chkhotua A (2011) Assessment of health-related quality of life in renal transplant recipients and dialysis patients. Transplant Proc 43(1): 376-369.

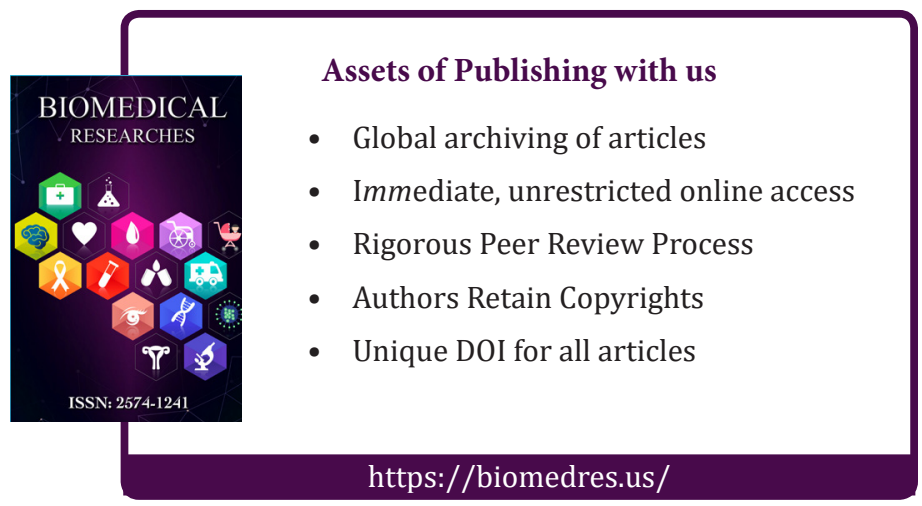

